\title{
Mutation Analysis of the BRCA1 and BRCA2 Genes in the Belgian Patient Population and Identification of a Belgian Founder Mutation BRCA1 IVS5+3A>G
}

\author{
Kathleen Claes, Eva Machackova, Michel De \\ Vos, Bruce Poppe, Anne De Paepe and \\ Ludwine Messiaen ${ }^{\#}$ \\ Department of Medical Genetics, University \\ Hospital Gent (0K5), De Pintelaan 185, B- \\ 9000 Gent, Belgium
}

\begin{abstract}
Since the identification of the BRCA1 and BRCA2 genes, several hundred different germline mutations in both genes have been reported. Recurrent mutations are rare and mainly due to founder effects. As the mutational spectrum of the BRCA1 and BRCA2 genes in the Belgian patient population is largely unknown, we initiated mutation analysis for the complete coding sequence of both genes in Belgian families with multiple breast and/or ovarian cancer patients and in "sporadic" patients with early onset disease. We completed the analysis in 49 families and in 19 "sporadic" female patients with early onset breast and/or ovarian cancer. In 15 families we identified a mutation (12 mutations in BRCA1 and 3 mutations in BRCA2). In 5 apparently unrelated families the same splice site mutation was identified (BRCA1 IVS5+3A>G). Haplotype analysis revealed a common haplotype immediately flanking the mutation in all families suggesting that disease alleles are identical by descent. In none of the 19 sporadic patients was a mutation found.
\end{abstract}

\footnotetext{
\# Correspondence: Ludwine Messiaen, PhD, Department of Medical Genetics, University Hospital Gent (0K5), De Pintelaan 185, B-9000 Gent, Belgium, Tel.: +32 9240 2478, Fax: +32 9240 4970, E-mail: Ludwine.Messiaen@ rug.ac.be
}

\section{INTRODUCTION}

In Belgium, the lifetime risk for women to develop breast cancer is $1 / 11$. In 5 to $10 \%$ of the cases the disease will occur as part of a hereditary cancer susceptibility syndrome [3]. A substantial proportion of hereditary breast cancers can be attributed to mutations in one of two genes, BRCA1 or BRCA2. In order to identify the mutational spectrum of the BRCA1 and BRCA2 genes in the Belgian patient population, we are currently performing mutation analysis for the complete coding sequence of both genes in Belgian breast and ovarian cancer patients as described [2]. When novel recurrent mutations are found, we evaluate whether they are due to a founder effect. We have completed the analysis in 49 families fulfilling our inclusion criteria and in 19 sporadic patients diagnosed with breast cancer before the age of 35 years.

\section{MATERIALS AND METHODS}

\section{Subjects}

We analysed 49 unrelated families (1) with at least 3 first degree relatives with breast and/or ovarian cancer diagnosed at any age; or (2) with at least 2 first and/or second degree relatives with breast and/or ovarian cancer diagnosed before the age of 45 years; or (3) with patients with bilateral breast cancer; or (4) with patients with both breast and ovarian cancer; 19 sporadic patients 
diagnosed with breast and/or ovarian cancer before the age of 35 years.

An informed consent was obtained from all participating individuals.

\section{Mutation detection}

As a first step BRCA1 exon 11 and BRCA2 exons 10 and 11 were analysed with the protein truncation test (PTT) [1,2]. Thereafter heteroduplex analysis (HA) was performed for those exons in which recurrent mutations have been identified in other populations, i.e. BRCA1 exons 2, 5, 13 and 20 and BRCA2 exons 7, 9, 20 and 23 [2]. Because our population geographically resides close to the Dutch region, the presence of genomic deletions encompassing exons 13 or 22 of BRCA1, both identified as Dutch founder mutations, was investigated by PCR as described [6]. We also performed PCR to detect the $6.4 \mathrm{~kb}$ duplication encompassing exon 13 of BRCA1 identified as an founder mutation in the Anglican population [7]. If at that stage no mutation was found, all remaining exons including the splice boundaries of both genes were analysed by heteroduplex analysis in a second step [2].

\section{Sequence analysis}

When aberrant mobility was detected on PTT or HA gels, the variants were sequenced using the Thermo Sequenase fluorescent-labeled primer cycle sequencing kit (Amersham). Samples were loaded on a 6\% LongRanger gel (FMC) containing $7 \mathrm{M}$ urea and analysed on an ALFTM detection system (Pharmacia).

When a mutation was identified, the analysis was repeated on a novel, seperately drawn blood sample of the patient before the result was communicated.

\section{Haplotype analysis}

Haplotype analysis was performed with 8 microsatellite markers (cen-THRA1-D17S800D17S855-D17S1322-D17S1323-D17S1327D17S1325-D17S1329-tel) as described [4].

Table 1

Phenotypes of Flemish families with a BRCA1/2 mutation

\begin{tabular}{|c|c|c|c|c|c|c|}
\hline \multirow[b]{3}{*}{ Gene and family } & \multirow[b]{3}{*}{ Mutation } & \multicolumn{4}{|c|}{ No. of cases of cancer } & \multirow[b]{3}{*}{ Other cancers } \\
\hline & & \multicolumn{2}{|c|}{ Female breast } & \multirow{2}{*}{$\begin{array}{c}\text { Male } \\
\text { breast }\end{array}$} & \multirow{2}{*}{$\begin{array}{c}\text { Ovarian } \\
\text { (ovarian } \\
\text { and } \\
\text { breast) }\end{array}$} & \\
\hline & & $\begin{array}{c}\text { At age }<50 \\
\text { years (bilateral) }\end{array}$ & $\begin{array}{c}\text { At age } \geq 50 \\
\text { years (bilateral) }\end{array}$ & & & \\
\hline \multicolumn{7}{|l|}{ BRCA1 } \\
\hline BR-32-030 & 185 insA & $4(1)$ & / & / & $1(1)$ & / \\
\hline BR-32-022 & IVS $5+3 \mathrm{~A}>\mathrm{G}$ & $3(2)$ & 2 & l & 3 & / \\
\hline BR-32-023 & IVS $5+3 \mathrm{~A}>\mathrm{G}$ & $2(1)$ & 1 & / & / & / \\
\hline BR-32-033 & IVS5+3A $>G$ & / & 1 & / & 2 & / \\
\hline BR-32-038 & IVS $5+3 \mathrm{~A}>\mathrm{G}$ & $4(2)$ & / & / & 1 & / \\
\hline BR-32-070 & IVS $5+3 \mathrm{~A}>\mathrm{G}$ & I & l & l & $2(1)$ & I \\
\hline BR-32-017 & 1191delC & 3 & l & l & / & Colon, throat, pancreas, lung \\
\hline BR-32-048 & E1221X & / & / & / & $1(1)$ & Endometrium \\
\hline BR-32-043 & Q1281X & $9(1)$ & 2 & / & / & Colon \\
\hline BR-32-001 & R1443X & $3(1)$ & 1 & / & $1(1)$ & Lung, leukemia, oesophagus \\
\hline BR-32-026 & IVS19+2delT & 1 & l & l & 1 & Colon \\
\hline BR-32-009 & IVS $22+5 G>A$ & 11 & 2 & / & 1 & Pancreas, prostate, stomach \\
\hline \multicolumn{7}{|l|}{$\underline{\text { BRCA2 }}$} \\
\hline BR-32-040 & 4075delGT & $3(1)$ & 3 & / & / & Liver, larynx \\
\hline BR-32-008 & 6503delTT & $2(1)$ & 1 & I & / & / \\
\hline BR-32-006 & 6831delTG & 2 & l & l & / & $\begin{array}{l}\text { Prostate, pancreas, liver, } \\
\text { colon }\end{array}$ \\
\hline
\end{tabular}




\section{RESULTS AND DISCUSSION}

Using this approach we identified a mutation in 15 (out of 49 ) unrelated families $(=30.6 \%$ ). Twelve mutations were identified in the BRCA1 gene and 3 mutations in the BRCA2 gene. Table 1 summarises the mutational and phenotypic data of the 15 families in which a mutation was found. Three mutations were not yet reported in other populations: i.e. mutation IVS5+3A>G (BRCA1), 1191delC (BRCA1) and 6831delTG (BRCA2).

In family BR-32-048 a single patient was diagnosed with breast (Dx53) and ovarian cancer (Dx55), but no other relatives have been diagnosed with cancer (hitherto) in this family. A mutation in the BRCA1 gene (E1221X) was identified in this patient.

Table 2 shows the number of breast and ovarian cancer cases per family and the frequency of BRCA1/2 mutations in the Flemish breast cancer and breast/ovarian cancer families that were analysed so far. Although the data are still limited, they give an indication of the phenotypes of families harbouring a mutation. Families with one or more cases of ovarian cancer are more likely to carry a BRCA1 mutation Among the families with no ovarian cancer cases mutations were more readily found in families containing more than one breast cancer case diagnosed at young age $(\mathrm{Dx}<40)$. In none of our families with a BRCA2 mutation was ovarian cancer present. In none of the families with male breast cancer was a mutation found, but only 2 families were studied so far.

The fact that in almost all families different mutations were found, confirms previous work stating that almost no recurrent mutations exist except for founder mutations and that every family bears its unique pathogenic mutation. However the splice site alteration in exon 5 of BRCA1 (IVS5+3 A>G) was identified in 6 apparently unrelated Belgian families (our results and [5]) and has never been reported in other populations. The mutation causes the deletion of the last 22 nucleotides of exon 5 at the cDNA level, leading to a frameshift and a premature stop codon. We performed haplotype analysis in all 5 families assessed in our centre. Table 3 shows the results for family BR-32-033, for which we had the opportunity to investigate an affected patient (VI.3) and her deceased mother diagnosed with ovarian cancer (on paraffin embedded tumour tissue). The alleles marked in

Table 2

Frequencies of breast and ovarian cancer cases and of BRCA1/2 mutations in 49 unrelated families

\begin{tabular}{|c|c|c|c|c|c|}
\hline $\begin{array}{c}\text { No. of female breast } \\
\text { cancers/family }\end{array}$ & $\begin{array}{l}\text { No. of ovarian } \\
\text { cancers/family }\end{array}$ & $\begin{array}{c}\text { Total No. of families [No. } \\
\text { of families with male } \\
\text { breast cancer] }(\mathrm{N}=49)\end{array}$ & $\begin{array}{c}\text { Total No. of } \\
\text { mutations } \\
(\mathrm{N}=15)\end{array}$ & $\begin{array}{c}\text { No. of families } \\
\text { with a BRCA1 } \\
\text { mutation }(\mathrm{N}=12)\end{array}$ & $\begin{array}{r}\text { No. of families } \\
\text { with a BRCA2 } \\
\text { mutation }(\mathrm{N}=3)\end{array}$ \\
\hline 1 & 0 & $1[1]$ & $0 / 1$ & 0 & 0 \\
\hline 2 & 0 & $3[1]$ & $1 / 3$ & 0 & 1 \\
\hline 3 & 0 & $10[0]$ & $3 / 10$ & 2 & 1 \\
\hline 4 & 0 & $5[0]$ & $0 / 5$ & 0 & 0 \\
\hline $5+$ & 0 & $15[0]$ & $2 / 15$ & 1 & 1 \\
\hline 1 & 1 & $1[0]$ & $1 / 1$ & 1 & 0 \\
\hline 2 & 1 & $1[0]$ & $0 / 1$ & 0 & 0 \\
\hline 4 & 1 & $1[0]$ & $0 / 1$ & 0 & 0 \\
\hline $5+$ & 1 & $3[0]$ & $2 / 3$ & 2 & 0 \\
\hline 0 & $2+$ & $1[0]$ & $0 / 1$ & 0 & 0 \\
\hline 1 & $2+$ & $3[0]$ & $2 / 3$ & 2 & 0 \\
\hline 2 & $2+$ & $1[0]$ & $1 / 1$ & 1 & 0 \\
\hline 3 & $2+$ & $1[0]$ & $0 / 1$ & 0 & 0 \\
\hline 4 & $2+$ & $1[0]$ & $1 / 1$ & 1 & 0 \\
\hline $5+$ & $2+$ & $2[0]$ & $2 / 2$ & 2 & 0 \\
\hline
\end{tabular}


Table 3

Results of the haplotype analysis of 1 Belgian family carrying the mutation BRCA1 IVS5+3A>G (maximum heterozygosity of the marker)

\begin{tabular}{|c|c|c|c|c|c|c|c|c|c|c|c|}
\hline $\begin{array}{l}\text { Marker(*) } \\
\text { (Max. het.) }\end{array}$ & CEN & $\begin{array}{c}\text { THRA1 } \\
(0.81)\end{array}$ & $\begin{array}{c}\text { D17S800 } \\
(0.74)\end{array}$ & $\begin{array}{c}\text { D17S8555 } \\
(0.82) \\
I V S 20 \\
\end{array}$ & $\begin{array}{c}\text { D17S1322 } \\
(0.67) \\
\text { IVS19 } \\
\end{array}$ & $\begin{array}{c}\text { D17S1323 } \\
(0.49) \\
I V S 13 \\
\end{array}$ & $\begin{array}{c}\text { IVS5+3 } \\
A>G\end{array}$ & $\begin{array}{c}\text { D17S1327 } \\
(0.58)\end{array}$ & $\begin{array}{c}\text { D17S1325 } \\
(0.88)\end{array}$ & $\begin{array}{c}\text { D17S1329 } \\
(0.81)\end{array}$ & $\begin{array}{c}\text { TE } \\
\mathbf{L}\end{array}$ \\
\hline \multirow{2}{*}{$\begin{array}{c}\text { BR-32-033 } \\
\text { VI.3 }\end{array}$} & & 166 & 168 & 148 & 120 & 153 & IVS5+3G & 132 & 199 & 188 & \\
\hline & & 170 & 170 & 148 & 120 & 153 & IVS5+3A & 132 & 199 & 188 & \\
\hline \multirow{2}{*}{$\begin{array}{c}\text { BR-32-033 } \\
\text { V.2 } \\
\text { (paraffin) }\end{array}$} & & 166 & 168 & 148 & 120 & 153 & IVS5+3G & 132 & 199 & 188 & \\
\hline & & 168 & 166 & 144 & 120 & 153 & IVS5+3A & 132 & 197 & 186 & \\
\hline
\end{tabular}

(*) Alleles are designated in basepairs

grey are segregating with the disease. We also performed haplotype analysis for the other 4 families in which a carrier of the BRCA1 IVS $5+3 A>G$ mutation was identified. Reconstruction of the haplotypes however was often impeded by the inaccessibility of material from close affected relatives. The results (data not shown) indicated that all families share identical haplotypes immediately flanking the mutation. In 2 families a recombination event had occurred: in family BR-32-022 between D17S855 and D17S1322 and in family BR-32070 between D17S800 and D17S855. All markers residing more proximal (i.e. closer to the mutation) had the same haplotype as that shown to segregate with the disease in family BR-32033. These results suggest that the alleles found in these breast cancer families may be identical by descent. Further haplotype analysis on paraffin embedded tumour tissue of deceased family members will allow us to completely define the haplotypes associated with the disease. Furthermore the prevalence of the BRCA1 IVS5 $+3 A>G$ associated haplotypes will be investigated in an unaffected Belgian control population.

All 5 families in which carriers of the BRCA1 IVS5 $+3 \mathrm{~A}>\mathrm{G}$ mutation were identified are living in the same geographic region of Flanders (WestVlaanderen).

In 4 of the families investigated ovarian cancer was present. Moreover, breast cancer was often diagnosed at a young age (Dx30-45). These results indicate that the BRCA1 mutation IVS5 $+3 A>G$ might be associated with a severe phenotype. Analysis in more Belgian families with breast and/or ovarian cancer will shed more light on the prevalence of this mutation in our population and on the phenotypes associated with this particular mutation.

In 19 women diagnosed with breast cancer before age 35, none of whom had a positive family history, no mutations have been identified. A larger population needs to be studied before conclusions concerning the benefit of mutation analysis in this population can be evaluated.

\section{Acknowledgments}

Supported by a research grant of the University of Gent (GOA 12051397) to K.C. and by a grant of the Fund for Scientific Research (F.W.O.) to B.P.

\section{References}

[1] Claes, K., Machackova, E., Callens, T., Van der Cruyssen, G. and Messiaen, L. Improved conditions for PTT analysis on BRCA1, BRCA2, NF1 and APC genes. Elseviers Trends Journal (1998) Technical Tips Online: t01457 (http://tto.trends.com).

[2] Claes, K., Machackova, E., De Vos, M., Mortier, G., De Paepe, A. and Messiaen, L. Mutation analysis of the BRCA1 and BRCA2 genes results in the identification of novel and recurrent mutations in 6/16 Flemish families with breast and/or ovarian cancer but not in 12 sporadic patients with early-onset disease. Human Mutation 13, (1998) 256.

[3] Claus, E.B., Schildkraut, J.M., Thompson, W.D. and Risch, N.J. The genetic attributable risk of breast and ovarian cancer. Cancer 77, (1996) 2318-2324. 
[4] Messiaen, L., Leroy, B.P., De Bie, S., De Pauw, K., Van Roy, N., Speleman, F., Van Camp, G. and De Paepe, A. Refined genetic and physical mapping of BPES type II. Eur. J. Hum. Genet. 4, (1996) 34-38.

[5] Peelen, T., van Vliet, M., Petrij-Bosch, A. et al. A high proportion of novel mutations in BRCA1 with strong founder effects among Dutch and Belgian hereditary breast and ovarian cancer families. Am. J. Hum. Genet. 60, (1997) 10411049.

[6] Petrij-Bosch, A., Peelen, T., van Vliet, M. et al, BRCA1 genomic deletions are major founder mutations in Dutch breast cancer patients. Nature Genetics 17, (1997) 341-345.

[7] Puget, N., Sinilnikova, O.M., Stoppa-Lyonnet, D. et al. An Alu-mediated $6 \mathrm{~kb}$ duplication in the BRCA1 gene: a new founder mutation? Am. J. Hum. Genet. 64, (1999) 300-302. 


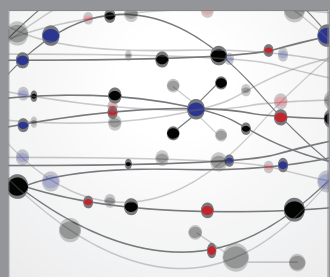

The Scientific World Journal
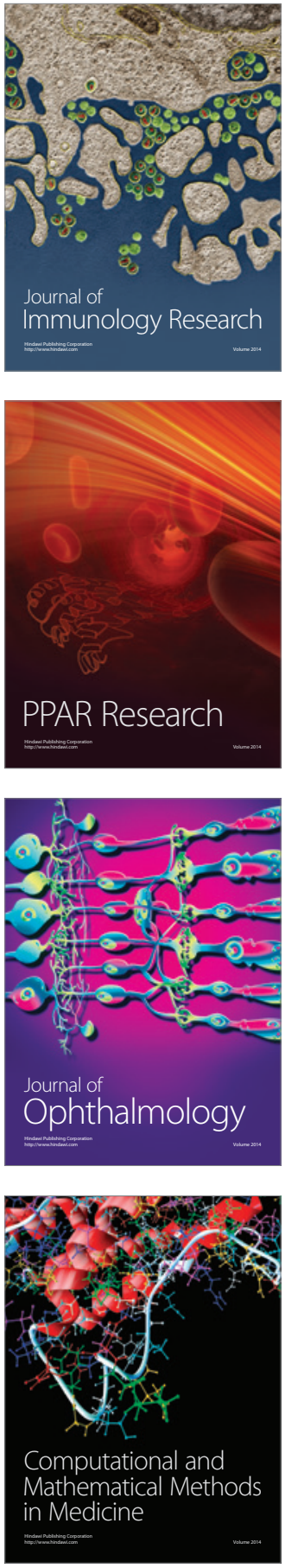

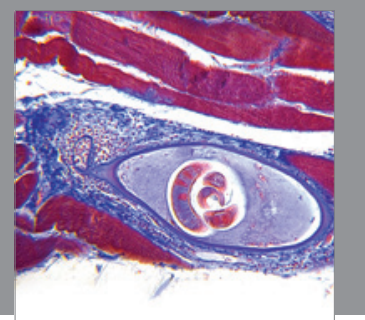

Gastroenterology

Research and Practice
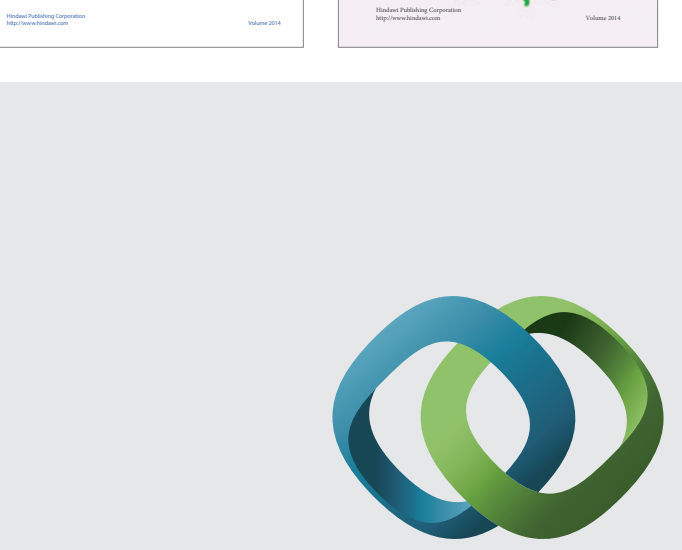

\section{Hindawi}

Submit your manuscripts at

http://www.hindawi.com
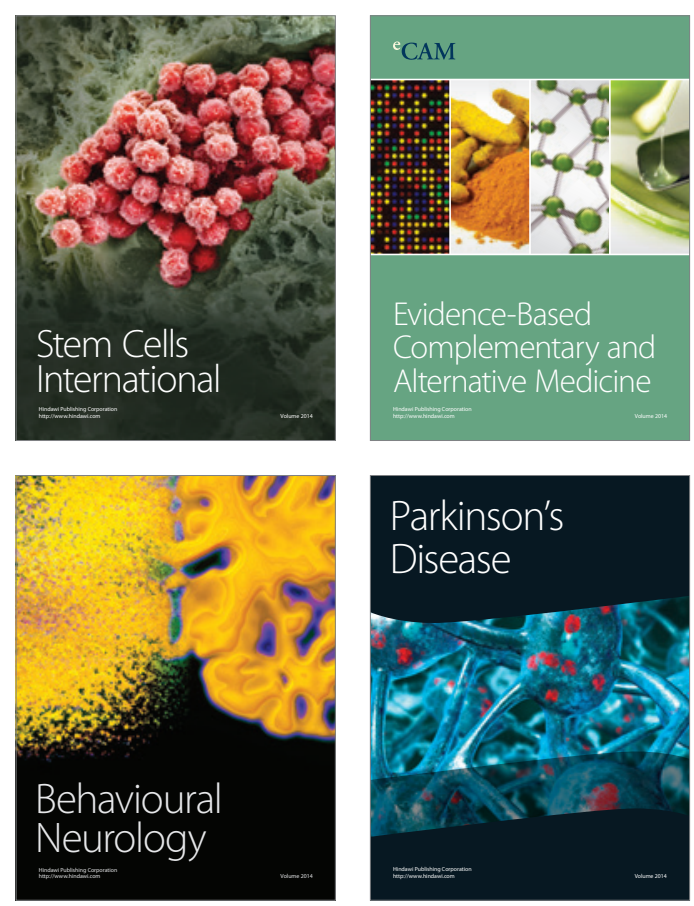

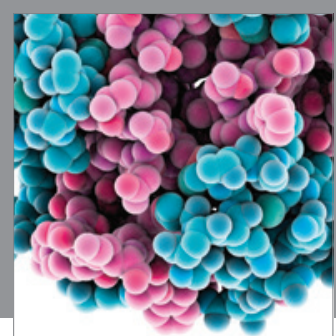

Journal of
Diabetes Research

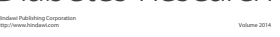

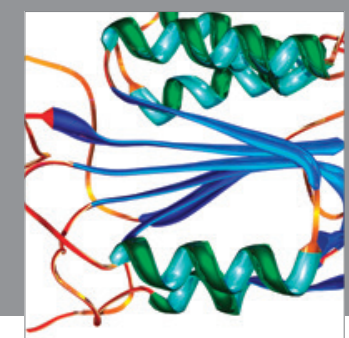

Disease Markers
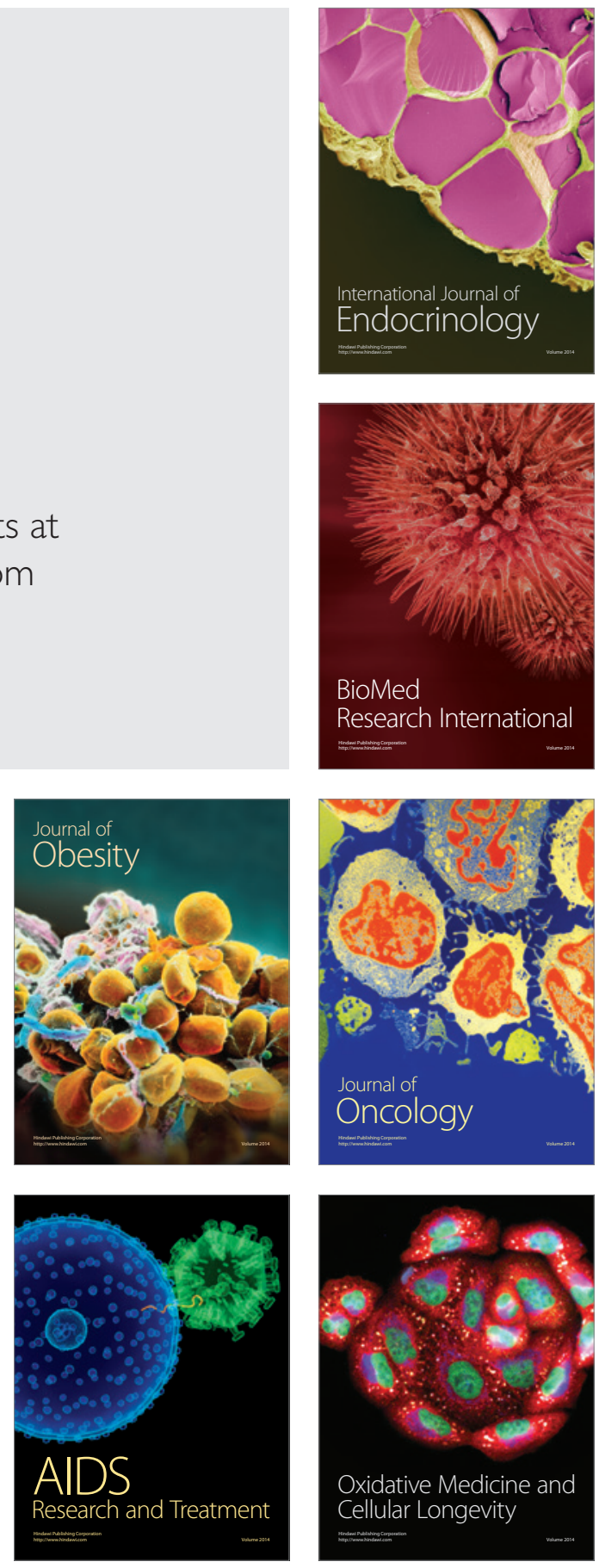